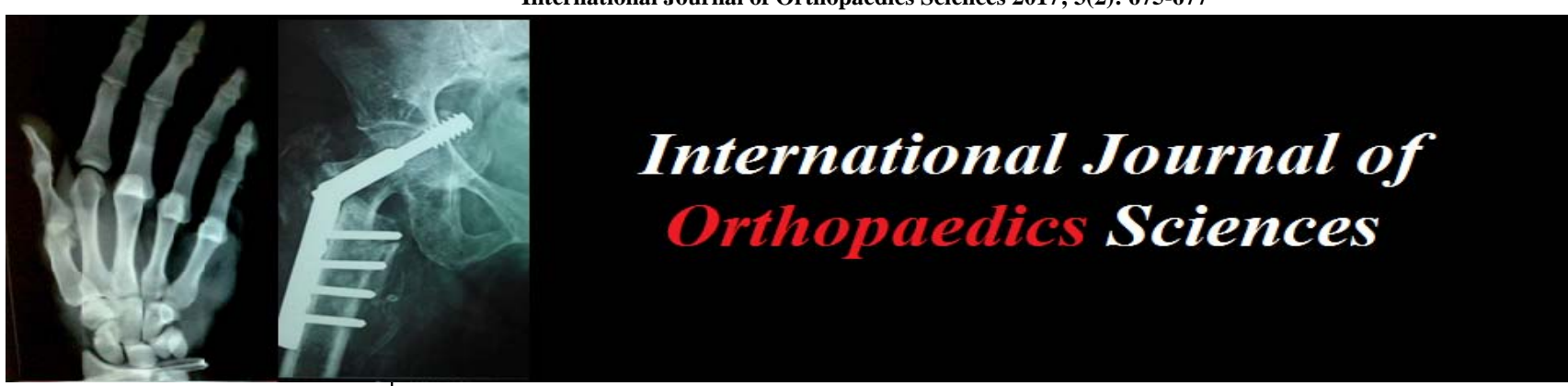

ISSN: $2395-1958$

IJOS 2017; 3(2): 675-677

(C) 2017 IJOS

www.orthopaper.com

Received: 09-02-2017

Accepted: 10-03-2017

\section{AN Mishra}

Professor, Orthopedics Surgery, Eras Medical College, Lucknow, Uttar Pradesh, India

\section{Sandhya Mishra}

Assistant Professor, Community Medicine, Integral Institute of Medical Sciences \& Research,

Lucknow, Uttar Pradesh, India

\section{HN Dhungana}

Assistant Professor, Community Medicine, Integral Institute of Medical Sciences \& Research, Lucknow, Uttar Pradesh, India

\section{Correspondence} Sandhya Mishra Assistant Professor, Community Medicine, Integral Institute of Medical Sciences \& Research, Lucknow, Uttar Pradesh, India

\section{A study of clinical evaluation of effectiveness of hydraulic distension of shoulder in the management of frozen shoulder}

\author{
AN Mishra, Sandhya Mishra and HN Dhungana
}

DOI: http://dx.doi.org/10.22271/ortho.2017.v3.i2g.69

\section{Abstract}

In this study we aim to evaluate clinical evaluation of outcome of treatment of frozen shoulder by hydraulic distension under local anesthesia with steroid. A rapid, immediate result and cost effectiveness of hydraulic distension technique was also evaluated is this study. There were 22 shoulders with good results after distension and 26 good results at follow up. In total there were 19 shoulders with excellent results at follow up, as compare to 2 shoulders with excellent results after distension. Patients who had detoriated revealed that they had failed to do regular prescribed home exercises. In contrast patients who had gained excellent results had their regular home exercises as prescribed to them. Hydraulic distension is a safe, reliable, cost effective modality in treating the chronically distressing painful condition of frozen shoulder.

Keywords: Frozen shoulder, hydraulic distension, clinical effectiveness

\section{Introduction}

The clinical term "Frozen shoulder" is a painful and debilitating condition with an incidence of $3 \%$ to $5 \%$ in the world population and up to $20 \%$ in those with diabetes ${ }^{[1-2]}$. The term 'frozen shoulder' was first introduced by Codman in 1934 to describe \& present a clinical condition that has been of interest to clinicians since the late $1800 \mathrm{~s}^{[3]}$. Frozen shoulder is an extremely disabling condition, presenting with and remitting shoulder pain and stiffness. Clinically it is characterized by considerable pain and insidious shoulder stiffness, which results in loss of passive and active forward flexion and external rotation. "Frozen shoulder" is a chronic condition of unknown etiology characterized by gradually progressive, painful restriction of all shoulder joint motion, with slow spontaneous restoration of either partial or complete motion over months to year. Management of frozen shoulder remains controversial. Codman, when he coined the term 'frozen shoulder', claimed that this disorder is 'difficult to define, difficult to treat, and difficult to explain from the point of view of pathology ${ }^{[1]}$. Frozen shoulder has been divided by Lundberg into two groups: Primary frozen shoulder and Secondary frozen shoulder. Primary frozen shoulder is diagnosed in the absence of a specific cause for the condition while secondary frozen shoulder develops as a result of trauma. Frozen shoulder involves 3 phases. These include the 'freezing phase' or the 'painful phase' lasting 3 to 8 months, the 'frozen phase' or the 'adhesive phase' lasting 4 to 12 months and the 'thawing phase' or 'resolution phase', which lasts anywhere from 12 months to 42 months and is characterized by a steady return of shoulder mobility and function ${ }^{[4]}$. The best techniques of conservative management of frozen shoulder has included combinations of regimens that include physiotherapy using a number of modalities, hydraulic distension of the glenohumeral joint and intra-articular steroid injections. While in operative management point of view early surgery has been shown to be of significant benefit for a faster recovery of pain, quicker recovery of function and earlier return to work (Hill Orthopaedics 1988, Doddonhoff JSES 2000). Arthroscopic capsular release has been shown to avoid the complications of manipulation under anaesthetic. It has the advantage of being able to identify any other associated pathologies. The management of frozen shoulder by giving treatment using hydraulic distension of the shoulder was popularized after it was found that arthrography of the shoulder in this condition produced alleviation of the pain and improved range of movement in a number of patients ${ }^{[3]}$. 
This procedure, called brisement, was commonly undertaken by radiologists ${ }^{[5-6]}$. Randomized controlled studies are few and suffer from small numbers, with poorly defined entry criteria. The types of treatment have included benign neglect, chiropractic manipulation, oral corticosteroids, and injection of corticosteroids, physiotherapy exercises, hydraulic distension with saline, manipulation under anesthesia and arthroscopic and open release of the contracture.

In this study we aim to evaluate clinical evaluation of outcome of treatment of frozen shoulder by hydraulic distension under local anesthesia with steroid. A rapid, immediate result and cost effectiveness of hydraulic distension technique was also evaluated is this study

\section{Methodology}

This study was a prospective experimental study involving 80 Patients with 88 shoulders of frozen shoulder, (of which 8 cases presented with bilateral shoulder involvement) attending the outpatient department of Orthopaedics, Era's Lucknow Medical college, Lucknow, Uttar Pradesh. All the patients were treated with hydraulic distension under local anesthesia along with intra articular steroid, on an outpatient basis. All these cases were treated from January to June 2016. Although different clinicians have indicated different range of restricted shoulder motion for a patient to be diagnosed as having frozen shoulder. In the study, we have used the diagnostic criteria used by Patrik. J. Mumaghan. According to this criteria, we included patients with progressive shoulder pain and stiffness with reduced movement, for which no specific cause was identifiable, and the patients with less than 30 degree of external rotation, less than 130 degree of forward elevation and less than 120 degree of abduction. There was variable limitation of internal rotation ${ }^{[7]}$.

\section{Results}

The average age of the patients enrolled in this study was as 54.16 years $( \pm 15.78$ years). Out of 80 patients, who completed the study, 52 were females and 28 males. In this clinical setting case series shows 8 patients $((10 \%)$ had bilateral involvement while in 33 patients (41\%) had involvement of the dominant side that is right shoulder, while 39 patients $(49 \%)$ were found to have left shoulder involvement. Few patients were found to have certain associated conditions such as 12 patients had diabetes mellitus, 10 patients had hypertension, 13 patients had osteoarthritis of knee, 1 patient diagnosed with peptic ulcer, and 3 patients of bronchial asthma were seen. 35 patients out of 50 patients $(70 \%)$ were previously treated with oral NSAIDs but without much relief. Five (10\%) patients also had been treated with steroidal intraarticular injection.

All the patients were managed with hydraulic distension under local anaesthesia and steroid without using any sedatives. The procedure was well tolerated by the patients and no complications were noticed during or post procedure.

All the patients were managed with hydraulic distension under local anaesthesia and steroid without using any sedatives. The procedure was well tolerated by the patients and no complications were noticed during or post procedure.

There were 7 shoulders with poor result after distension of which one shoulder did not improve even at follow up.

23 shoulders had fair results after distension, and only 8 shoulders had fair results at follow up.

There were 22 shoulders with good results after distension and 26 good results at follow up. In total there were 19 shoulders with excellent results at follow up, as compare to 2 shoulders with excellent results after distension. Patients who had detoriated revealed that they had failed to do regular prescribed home exercises. In contrast patients who had gained excellent results had their regular home exercises as prescribed to them.

Two cases were given $2^{\text {nd }}$ trial of hydraulic distension but there was no improvement.

Frozen shoulder with severe restriction of motion in range of movements less than 60 degrees very minimal improvement was seen. In shoulder who had initial range of movements of 60 to 100 degrees showed better results? The best results were seen in shoulder who had range of movements more than 100 degrees.

\section{Discussion}

Frozen shoulder, though common, is least understood condition, causing pain in the shoulder. One of the earliest descriptions of the pathology of a frozen shoulder was by Neviaser, in 1945, who found thickened, contracted capsule around the humeral head. Histology of the capsule showed fibrosis and inflammatory cells ${ }^{[3]}$. Frozen shoulder is believed to be a primarily inflammatory reaction in the capsule and synovium that subsequently leads to the formation of adhesions, characteristically in the axillary fold and in the attachment of the capsule at the anatomical neck of the humerus ${ }^{[6]}$.

Review of the previous literature on treatment options of the condition revealed a lack of consensus on a universally accepted modality for the patient. A number of different treatments have been described, including general measures such as rest and neglect to analgesics, NSAIDS, local or oral steroids, physiotherapy, distension of the joint capsule, manipulation. Recently arthroscopic treatment and surgical release has also been recommended for this condition ${ }^{[8]}$. More than often, a combination of these modalities has been advocated. No standard treatment regime is universally accepted.

Some studies have found that local steroid injection provided pain relief to the patients but often failed to restore adequate ROM and also had no superior effect on the duration of symptoms compared with other treatments including heat, physiotherapy, ice, local analgesic injections, manipulation or no treatment. Other studies have reported that local steroids were without advantage when compared to physiotherapy or oral no steroidal anti-inflammatory drugs. Manipulation of the shoulder under general anesthesia with an intra-articular steroid and local anesthesia injection has been recommended for frozen shoulder. However, this requires a more costly inpatient stay with general anesthesia and immediate postoperative physiotherapy. There are also risks of fracture of the humeral neck and rupture of the rotator cuff when the procedure is performed by an inexperienced surgeon ${ }^{[9]}$.

Hydraulic distension of the shoulder joint capsule initially described by Halverson L, Maas R., has potential to provide rapid relief of pain and immediate improvement of shoulder function for patients with frozen shoulder. They have reported that $94 \%$ of the patients had improved mobility immediately after the procedure. $53 \%$ of the patients had immediate, short term, and sustained improvement in comfort and function ${ }^{[10]}$. In our study, we found that during post distension period, $8 \%$ of the patients had excellent results, $48 \%$ good results, $40 \%$ fair results and $12 \%$ had poor results. At follow up $44 \%$ had excellent results, $50 \%$ had good results, $12 \%$ had fair results and $2 \%$ had poor results. A similar study conducted by Khan $\mathrm{AA}$, et al., compared distension arthrography with intra- 
articular steroid plus physical therapy versus physical therapy alone and concluded that distension arthrography with intraarticular steroid plus physical therapy was superior over physical therapy alone in the functional improvement of the frozen shoulder. Quraishi et al in their prospective study have recommended hydrodistension for patients with frozen shoulder resistant to conservative treatment. Manipulation under anaesthesia is a more costly inpatient procedure, whereas hydrodilatation can be carried out as an outpatient without general anaesthetic. There is also the risk of humeral neck fracture and rupture of the rotator cuff during manipulation under anaesthesia ${ }^{[11]}$. Our study had absolutely no complication or side effect except for mild pain during hydraulic distension. On the basis of the findings in our study we recommend that patients with frozen shoulder should be treated with hydraulic distension under local anesthesia with steroid because this technique is safe and cost effective.

\section{Conclusion}

Hydraulic distension is a safe, reliable, cost effective modality in treating the chronically distressing painful condition of frozen shoulder. This therapy can be practiced as an outpatient without any specialized equipments, and when performed with a right technique under aseptic precautions, it has absolutely no side effects. Hence, we conclude that hydraulic distension under local anesthesia with steroid can be considered as a first line management option in patients with frozen shoulder.

Table 1: Pain score

\begin{tabular}{|c|c|c|c|}
\hline Score & $\begin{array}{c}\text { Pre } \\
\text { Distension }\end{array}$ & $\begin{array}{c}\text { After Hydraulic } \\
\text { Distension }\end{array}$ & $\begin{array}{c}\text { At Follow Up (6 Weeks) } \\
\text { Post Distension) }\end{array}$ \\
\hline 0 & 1 & 0 & 0 \\
\hline 1 & 17 & 6 & 0 \\
\hline 2 & 16 & 15 & 4 \\
\hline 3 & 20 & 24 & 10 \\
\hline 4 & 0 & 9 & 34 \\
\hline 5 & 0 & 0 & 6 \\
\hline
\end{tabular}

Table 2: Range of Movement

\begin{tabular}{|c|c|c|c|}
\hline ROM & $\begin{array}{c}\text { Pre- } \\
\text { Distension }\end{array}$ & $\begin{array}{c}\text { After Hydraulic } \\
\text { Distension }\end{array}$ & $\begin{array}{c}\text { At Follow Up } \\
\text { (6 Weeks Post } \\
\text { Distension) }\end{array}$ \\
\hline 0-60 deg & 25 & 14 & 2 \\
\hline 61-100deg & 29 & 24 & 20 \\
\hline 101-140deg & 0 & 16 & 32 \\
\hline
\end{tabular}

Table 3: Functional Score

\begin{tabular}{|c|c|c|c|}
\hline $\begin{array}{c}\text { Functional } \\
\text { Score }\end{array}$ & $\begin{array}{c}\text { Pre- } \\
\text { Distension }\end{array}$ & $\begin{array}{c}\text { After Hydraulic } \\
\text { Distension }\end{array}$ & $\begin{array}{c}\text { At Follow Up } \\
\text { (6 Weeks Post } \\
\text { Distension) }\end{array}$ \\
\hline 0 & 6 & 1 & 0 \\
\hline 1 & 12 & 5 & 0 \\
\hline 2 & 19 & 22 & 9 \\
\hline 3 & 16 & 23 & 23 \\
\hline
\end{tabular}

Table 4: Functional Score

\begin{tabular}{|c|c|c|c|}
\hline $\begin{array}{c}\text { Functional } \\
\text { Score }\end{array}$ & $\begin{array}{c}\text { Pre- } \\
\text { Distension }\end{array}$ & $\begin{array}{c}\text { After } \\
\text { Hydraulic } \\
\text { Distension }\end{array}$ & $\begin{array}{c}\text { At Follow Up } \\
\text { (6 Weeks Post } \\
\text { Distension) }\end{array}$ \\
\hline 0 & 6 & 1 & 0 \\
\hline 1 & 12 & 5 & 0 \\
\hline 2 & 19 & 22 & 9 \\
\hline 3 & 16 & 23 & 23 \\
\hline
\end{tabular}

Table 5: Functional Score

\begin{tabular}{|c|c|c|c|}
\hline $\begin{array}{c}\text { Functional } \\
\text { Score }\end{array}$ & $\begin{array}{c}\text { Pre- } \\
\text { Distension }\end{array}$ & $\begin{array}{c}\text { After } \\
\text { Hydraulic } \\
\text { Distension }\end{array}$ & $\begin{array}{c}\text { At Follow Up } \\
\text { (6 Weeks } \\
\text { Post Distension) }\end{array}$ \\
\hline 0 & 6 & 1 & 0 \\
\hline 1 & 12 & 5 & 0 \\
\hline 2 & 19 & 22 & 9 \\
\hline 3 & 16 & 23 & 23 \\
\hline
\end{tabular}

Table 6: Overall results

\begin{tabular}{|c|c|c|c|c|}
\hline \multirow{2}{*}{ Results } & \multicolumn{2}{|c|}{ No. of Shoulders } & Percentage & \\
\cline { 2 - 5 } & Post Distension & Follow Up & Post Distension & Follow Up \\
\hline Excellent & 2 & 19 & 4 & 38 \\
\hline Good & 22 & 26 & 44 & 52 \\
\hline Fair & 23 & 8 & 46 & 16 \\
\hline Poor & 7 & 1 & 14 & 2 \\
\hline
\end{tabular}

\section{References}

1. Jacobs LG, Barton MA, Wallace WA et al. Intra-articular distension and steroids in the management of capsulitis of the shoulder. BMJ. 1991; 302:1498-1501. [PMC free article] [PubMed]

2. Rowe CR, Leffert RD. Idiopathic chronic adhesive capsulitis ("frozen shoulder") In: Rowe CR, editor. The Shoulder. New York: Churchill Livingstone, 1988, 155163.

3. Jacobs LG, Smith MG, Khan SA, Smith K. Manipulation or intra-articular steroids in the management of adhesive capsulitis of the shoulder? A prospective randomized trial. J Shoulder Elbow Surg. 2009; 18:348353. [PubMed]

4. Manske RC, Prohaska D. Clinical commentary and literature review: diagnosis, conservative and surgical management of adhesive capsulitis. Shoulder \& Elbow. 2010; 2:238-54.

5. Mulcahy KA, Baxter AD, Oni OO, Finlay D. The value of shoulder distension arthrography with intraarticular injection of steroid and local anaesthetic: a follow-up study. Br J Radiol. 1994; 6:263-236. [PubMed]

6. Rizk TE, Gavant ML, Pinals RS. Treatment of adhesive capsulitis (frozen shoulder) with arthrographic capsular distension and rupture. Arch Phys Med Rehabil. 1994; 75:803-807. [PubMed]

7. Murnaghan JP. Frozen shoulder. Chapter 21. In: Rockwood CA Jr (editor). The shoulder. Philadelphia: W.B. saunders company. 1990; 2:837-862.

8. Halverson L, Maas R. Shoulder joint capsule distension (hydroplasty): a case series of patients with frozen shoulders treated in a primary care office. J Fampract. 2002; 51(1):61-63.

9. Quraishi NA, Johnston P, Bayer J, Crowe M, Chakrabarti, AJ. Thawing the frozen shoulder A randomised trial comparing manipulation under anaesthesia with hydrodilatation. J Bone Joint Surg [Br]. 2007; 89-B:1197-200. 